ARTICLE

\title{
Targeted management buffers negative impacts of climate change on the hihi, a threatened New Zealand passerine
}

\author{
David L. P. Correia ${ }^{a, 1}$, Aliénor L. M. Chauvenet ${ }^{b, 1,2}$, J. Marcus Rowcliffe ${ }^{b}$, John G. Ewen \\ a Imperial College London, Silwood Park, Ascot, Berkshire SL5 7PY, UK \\ ${ }^{b}$ Institute of Zoology, Zoological Society of London, Regent's Park, London, NW1 4RY, UK \\ * Corresponding author: Aliénor L. M. Chauvenet; Centre for Biodiversity and Conservation \\ Science, School of Biological Science, Goddard bldg. 8, University of Queensland, St Lucia, \\ QLD, 4072, Australia; Telephone:+6173346 7541; E-mail: a.chauvenet@uq.edu.au.
}

\begin{abstract}
In order to buffer the risks climate change poses to biodiversity, managers need to develop new strategies to cope with an increasingly dynamic environment. Supplementary Feeding (SF) is a commonly-used form of conservation management that may help buffer the impacts of climate change. However, the role of SF as an adaptation tool is yet to be fully understood. Here we used the program MARK to quantify the relationship between weather (average temperature and total precipitation) and vital rates (survival and recruitment) of an island bird population, the hihi Notiomystis cincta, for which long term demographic data are available under periods of little and ad libitum SF. We then used predictive population modelling to project this population's dynamics under each management strategy and several climate change scenarios in accordance with the Intergovernmental Panel on Climate Change predictions. Our stochastic population projections revealed that ad libitum SF likely buffer the population against heavier rainfall and more stochastic precipitation patterns; no buffering effect on temperature was detected. While the current SF approach is unlikely to prevent local extinction of the population under increasing temperatures, SF still presents itself as a valuable climate change adaptation tool by delaying extinction. To the best of our knowledge, this is the first study to quantify the interaction between climate and SF intensity of a threatened population. We call for on-going critical evaluation of management measures, and suggest that novel adaptation solutions that combine current approaches are required for conserving species with limited opportunity for dispersal.
\end{abstract}

Keywords: Supplementary feeding, stitchbird, conservation, climate change adaptation, modelling, population dynamics

\section{Introduction}

Climate change is an emergent global threat and is expected to become one of the major drivers of species extinctions of the $21^{\text {st }}$ century (Foden et al., 2013). According to the Intergovernmental Panel on Climate Change (IPCC), through to year 2100 mean global surface temperatures will increase somewhere between $0.3^{\circ} \mathrm{C}$ and $4.8^{\circ} \mathrm{C}$, average annual precipitation will increase significantly in some areas while declining in others and global average sea level and temperature will continue to rise (IPCC, 2013). Furthermore, even if

\footnotetext{
1 Both authors contributed equally and have shared first authorship

2 Present address: Centre for Biodiversity and Conservation Science, School of Biological Science, Goddard bldg. 8, University of Queensland, St Lucia, QLD, 4072, Australia
} 
$\mathrm{CO}_{2}$ emissions were to be curbed by successful mitigation strategies, most aspects of climate change will most likely be felt for centuries to come (IPCC, 2013).

These modifications of the Earth's climate could have devastating consequences for global biodiversity. Indeed, Foden et al. (2013) found $11-15 \%$ of the world's amphibians and $6-9 \%$ of bird and coral species worldwide are both highly vulnerable to climate change and threatened with extinction according to the IUCN Red List. Documented climate change impacts include the poleward expansion of distribution ranges (Hickling et al., 2006), altitudinal shifts in distribution (Lenoir et al., 2008), phenological effects such as shifts in timing of breeding (Crick et al., 1997) and reduction of genetic diversity due to directional selection (Bellard et al., 2012). Additionally, climate has been reported to have strong effects on vital rates such as breeding success and survival, so changes in climate are certain to reflect on population demography (Jenouvrier, 2013).

As many species may be unable to either adapt or migrate in response to climate change (Jump and Peñuelas, 2005), in situ management strategies will likely play an essential role in the future of conservation. Implementing adaptation strategies, which attempt to adjust the natural systems both to the actual and to the expected climate (IPCC, 2012), offers one alternative to conserve species under threat from climate change. Adaptation strategies for species can be broadly categorised as having two distinct goals: (1) shifting or facilitating the expansion of species distribution ranges (e.g. building corridors to increase connectivity, habitat restoration) and (2) improving species' capacity to cope with less favourable climate conditions within their original range (e.g. food or shelter provisions, creation of buffer zones) (Heller and Zavaleta, 2009). Different strategies will have different costs, and one of the cheaper strategies is supplementary feeding (SF). The benefits of SF for threatened species are well-documented (although see (Clout et al., 2002) for a caution): SF provides safe food sources (Wilbur et al., 1974), improves vital rates (Elliott et al., 2001) and leads to increases in size of small populations (Cabezas and Moreno, 2007; Chauvenet et al., 2012). However, while SF is widespread (e.g. García-Ripollés, López-López \& García-López 2004; González et al. 2006; Schoech et al. 2008), the role it has on buffering the impact of changing climate conditions on managed populations remains largely unknown.

SF has the potential to buffer impacts of climate change on food availability, which is usually one of the most significant ways climate influences bird populations (Hulme, 2005). For example, SF could help nectivorous species adapt to the expected disruption of flowering dates (Clark and Thompson, 2010). In particular, SF may act as a surrogate nectar or fruit source to: (i) replace plant species expected to become either locally or globally extinct due to climate change (Thuiller et al., 2005); and (ii) compensate for plant mortality and reduced nectar production caused by severe droughts (Forrest, 2015). Hence, SF is likely to reduce environmental stochasticity by improving food source reliability. For example, the use of SF has been implemented by reindeer (Rangifer tarandus) herders to boost reindeer resilience to climate change (Furberg et al., 2011). Unfortunately, there is a lack of empirical studies on how the expected benefits of SF on species viability may be influenced by climate change. It is therefore necessary to understand better how adaptation strategies such as SF can compensate for declining habitat suitability due to climate change.

Here we use a long-term study of the hihi, Notiomystis cincta, to test how well SF performs as a climate change adaptation strategy. It is a threatened endemic New Zealand passerine bird, which is restricted to small isolated populations in a highly fragmented landscape. Island-restricted passerines, like the hihi, represent a useful system to examine the relationships between management interventions and climate due to their restricted range, annual reproduction, relatively easy capture and estimation of demographic parameters (Chauvenet et al., 2012). Moreover, hihi population dynamics are known to be influenced by climate conditions, with increases in temperature resulting in a predicted reduction in population size and increased extinction probability (Chauvenet et al., 2013). Chauvenet et 
al. (2013) predicted that climate change will reduce the suitability of habitat within the current range of hihi and that suitable habitat will migrate southwards. The predictions of reduced population viability of hihi are based largely on detailed demographic and climatic data available from one island population (Tiritiri Matangi) that receives continuous ad libitum SF. It is difficult, therefore, to quantify any effects SF is having on buffering this population's response to predicted changes in climate conditions. However, another hihi population, on Kapiti Island, offers an ideal model to quantify how SF performs as a potential climate change adaptation tool due to 17 years (1993-2009) of monitoring population demographics coupled with prolonged periods of both minimal SF and extensive ad libitum SF.

The aim of this study was to explore the potential of SF to buffer animal populations against environmental change and increased environmental stochasticity, and try to further our understanding of the relationship between SF and climate in general. We defined a "buffering effect" as a reduction of environmental noise responsible for variations in demographic rates (Grimm et al., 2005). This means the effect of climate on vital rates or abundance of a species was expected to be dampened by SF, and thus less detectable in periods of intense SF than when there was little or no SF.

We first tested if weather variables influenced the vital rates and abundance of the hihi population on Kapiti Island under two different supplemental feeding regimes. We expected these demographic parameters to be affected by fluctuations in mean temperature or precipitation and by changes in the standard deviation (SD) of weather parameters, as previously reported for another hihi population (Chauvenet et al., 2013) (H1), but significantly less so under an ad libitum feeding regime when compared to periods with minimal SF $(\mathrm{H} 2)$. Although direct relationships between climate and hihi demography have been reported (Chauvenet et al., 2013), the exact mechanisms driving these interactions are unknown. Enhanced understanding of this system could shed light on the exact nature of such mechanisms. Improved knowledge of the relationships between hihi demography, SF and climate was then used to develop predictive population models with the objective of forecasting the role of SF in reducing extinction risk in the face of climate change. We expected that the implementation of ad libitum SF would reduce the estimated extinction risk of the population $(\mathrm{H} 3)$.

\section{Materials and Methods}

\subsection{Study Species and Site}

Kapiti Island is a small island (c. 1965 ha) located approximately $5 \mathrm{~km}$ off the west coast of New Zealand's lower North Island. Kapiti is forested in several distinct types of native vegetation, particularly mixed broadleaf forest, kohekohe (Dysoxylum spectabile) and rata (Metrosideros robusta) (Esler, 1967).

Hihi are medium sized passerines (males c. $40 \mathrm{~g}$; females $c .30 \mathrm{~g}$ ) with a generalist diet of approximately equal proportions of nectar, fruit and invertebrates. Although once widespread across northern New Zealand they had become restricted to a single offshore island (Hauturu or Little Barrier Island) by about 1890. Beginning in 1980, a reintroduction program has resulted in five additional reintroduced and managed hihi populations in isolated locations across their former range (Ewen et al., 2014a). Hihi were first reintroduced to Kapiti Island in 1983 but these initial releases failed to establish a population. Renewed reintroduction efforts were made in the early 1990's (1990, $N=12 ; 1991, N=48 ; 1992, N=$ 47) and a small population persisted on the island with limited SF until 2000. Limited SF involved one or two feeders providing sugar water (20\% by mass) available during the breeding season ( $<100$ litres annually). In contrast, between 2000 and 2009 SF was ad libitum year round. This change followed research on other hihi populations showing the benefit of SF (Armstrong \& Ewen 2001; Armstrong et al. 2007). There were nine feeders, five of which were active all year round and located in the middle of the island, where the hihi 
population is restricted. During ad libitum feeding extensive amounts of sugar water was provided, peaking at an estimated 3638 litres annually (Chauvenet et al. 2012).

Experience with this population suggested that the feeders were accessible to the entire population: the island is relatively small and hihi are known to travel several kilometres between favourite feeding sites (DOC, 2005). Sugar water has been the preferred supplement to provide carbohydrates to the population, partly because it is cheap and persists longer in feeding stations without going off compared to alternative supplements. More complete dietary supplements (e.g. those rich in proteins and fats) have been used occasionally in other hihi populations but experiments have also revealed they either provided little additional benefit to population growth rates (Armstrong et al. 2007) or had sex specific costs on nestling survival (Walker et al. 2012). The hihi population on Kapiti was estimated to have increased from fewer than 20 individuals in 2000 to over 160 in 2009 (Chauvenet et al., 2012). The population has been closely monitored since 1991 and detailed weather data are available from the New Zealand National Institute of Water and Atmospheric Research's weather station in Paraparaumu, which is located approximately $5 \mathrm{~km}$ from Kapiti Island, on the nearby mainland coast. Between 1993 and 2009 average temperature was approximately $10.76^{\circ} \mathrm{C}(\mathrm{SD}=0.38)$ during the non-breeding season and $14.8^{\circ} \mathrm{C}(\mathrm{SD}=0.47)$ during the breeding season and average total precipitation was $448.9 \mathrm{~mm}(\mathrm{SD}=101.33)$ during the non-breeding season and $562.2 \mathrm{~mm}(\mathrm{SD}=140.16)$ during the breeding season.

\subsection{Data Collection}

Since 1990, a pre-breeding population census has been completed on Kapiti every Austral spring in October. Each entails about 36 hours of search effort, most of which are spent watching the SF stations. During these censuses an equal amount of time is spent watching the feeders during the morning and during the afternoon.

Most hihi are banded as juveniles between January and March. Given that very few unbanded birds are seen throughout the breeding season, banding on the island appears to be successful at marking the majority of surviving juveniles from the previous season. Reported recapture rates are also very high (Chauvenet et al., 2012). Therefore, we assumed that all unbanded hihi caught in an October survey were one year old adults and we have modified the capture history dataset slightly to reflect this assumption. This allowed much more robust age-related variables to be considered in the demographic models and only affected $c .10 \%$ of all individuals captured. This assumption was based on expert understanding of hihi ecology. The continual effort invested in banding means the most likely reason an unbanded adult is present is because it was last years young. We thus believe that our assumption did not impact our results significantly.

\subsection{Estimating abundance, recruitment, survival and recapture}

We estimated abundance, recruitment, survival and recapture rates of the hihi population on Kapiti using the programme MARK (Cooch and White, 2012), in R v.3.0.1 (R Development Core Team, 2013). In order to assess the fit of the models to the data, c-hat values were calculated using the RELEASE Goodness of Fit test (Arnason and Schwarz, 1999), as it is considered to be more robust than bootstrapped and median c-hat estimates for data based solely on live encounters (Cooch and White, 2012). Over-dispersion was corrected for using the c-hat adjustment in MARK. Hence, model selection used QAICc rather than AICc values (Cooch and White, 2012). The model selection cut-off value considered was always $\triangle$ QAICc $<2$ (Burnham and Anderson, 2002).

Two different types of models were developed to estimate distinct parameters: (1) POPAN models were used to estimate abundance, which will later be used to model densitydependence on vital rates, and (2) Pradel-recruitment models were built to estimate survival rates and recruitment. POPAN models estimate four different parameters: $\varphi_{\mathrm{i}}$ (probability of 
an individual surviving between occasions $i$ and $i+1), p_{i}$ (probability of capture at occasion i), $N$ (super-population that includes all animals that will ever be recruited into the population) and pent $_{i}$ (probability that an individual from the super-population $N$ enters the population between occasion $i$ and $i+1$ ) (Cooch and White, 2012). Pradel-recruitment models estimate three parameters, two of which were also being estimated in the POPAN models: $\varphi_{i}$ and $p_{i}$. The final parameter, $f_{i}$, is a measure of net recruitment which represents the number of new individuals that enter the population per breeding adult in year $i$ that are still alive by $i+1$ (Cooch and White, 2012). All covariates investigated for each parameter of the POPAN and the Pradel-recruitment models are detailed in Table 1.

The demographic model selection process is summarized in Fig. A1 in the supplementary material. We started by developing three alternative full models for both POPAN and Pradelrecruitment formulations, including all the covariates for survival rates listed in Table 1 (except the interaction terms), but with either breeding season, non-breeding season or annual climate variables (temperature and precipitation; $\mathrm{H} 1$ \& $\mathrm{H} 2$ ). Non-climate variables (age and sex) were also included in the analysis in order to account for possible significant impacts on population demography that were not directly related to climate or SF. At this point recruitment rates (POPAN's probability of entry in the population pent and Pradelrecruitment $f$ ) were considered to be time-dependent. In order to reduce the model candidate set, we set POPAN's super-population size $N$ as always constant and $p$ as always timedependent for both model types (Chauvenet et al., 2012).

In a second step we decomposed the most parsimonious model(s) from the previous step $(\triangle \mathrm{QAICc}<2)$ into simpler models. Several smaller models were built to analyse every possible combination of survival covariates from the previous, larger models, including weather, SF and demographic covariates. This process refined the list of covariates of survival. For Pradel-recruitment models only, we increased the candidate model set by adding abundance and possible interactions with SF regime into the models. This step was meant to account for any possible density dependence effects on vital rates.

In a final step, interactions between SF regime types and each of the climate variables were tested within the new set of most parsimonious models for survival from step 2. The most parsimonious models of a given step were always included, unchanged, in the candidate model set of the following step.

The same three-step process was then repeated to investigate covariates of Pradelrecruitment's $f$. For this model survival was defined according to the best model found. POPAN's pent was considered to be solely time-dependent (Table 1).

When no single plausible model was identified for either the POPAN or the Pradelrecruitment analysis (more than one model with $\triangle$ QAICc $<2$; (Burnham and Anderson, 2002); all plausible models were averaged in order to reduce the uncertainty in model selection (see Supplementary material A for detailed model averaging methodology; Burnham and Anderson, 2002).

One issue that will impact our results concerning the climate buffering effect of SF on demographic rates, is that demographic rates of a rapidly growing population are inherently different from those of a population regulated at a low carrying capacity. Density dependence and carrying capacity is likely to be different between a population receiving limited SF and one receiving ad libitum SF. In order to ascertain the relationship between SF and climate, we thus needed to compare the population when it was stable with and without SF while including abundance as a covariate. Hence, we repeated our modelling procedure for a subset of the original dataset (henceforth, equilibrium analysis). In the equilibrium analysis the ad libitum SF time-series was constrained to the most stable snapshot of the population under ad libitum SF (2005-2009) and compared to the period when SF was limited (1993-1999). We identified 2005-2009 as a period of population stability based on examination of the abundance figures for this population published by Chauvenet et al. 
(2012); this was when population growth stabilized despite ad libitum SF, a possible side effect of negative density dependence on recruitment induced by reaching a new carrying capacity. As each dataset (complete dataset and equilibrium dataset) has its own specific limitations (namely a possible confounding effect between environmental buffering and population growth in the former and a potential lack of statistical power in the latter), both results are reported.

\subsection{Population Dynamics Modelling}

We built stochastic sex-specific population dynamics models in the software $R$ to project the hihi population of Kapiti Island in the future under various climate change scenarios for both the complete and the equilibrium datasets. Breeding and non-breeding survival rates, as well as recruitment rate, were defined by the relationships between vital rates and climate (and other variables) found in the previous step (see Pradel-Recruitment averaged model parameters; Table C1 in Supplementary material). At each time-step, values for the climate variables (average temperature and precipitation) were sampled on normal distributions with mean and standard deviation depending on the scenario modelled. For example, if modelling the baseline conditions, values would be based on observed climatic conditions during breeding and non-breeding seasons. Initial abundance was always set to reflect the estimated post-breeding population size in 2009 according to the complete dataset (173 individuals of which 41 were 1 year olds). Environmental carrying capacity was set at 200 individuals (reflecting expert belief from the local hihi recovery team); to implement it, if the population number reached above 200 , the extra individuals were removed.

The objective was to quantify the potential impacts of future climate change on the average population size of hihi on Kapiti over 100 years, as well as how SF may influence these impacts; we also recorded probability and average time of pseudo-extinction of the population by counting the number of simulations where the population dropped below 5 individuals and the time-step of the simulation when this happened Several different climate change scenarios were investigated according to the RCP4.5 scenario projected by the IPCC (IPCC, 2013). Scenarios tested included increases in average temperature, decreases in total rainfall and changes in rainfall standard deviation (Table 2). The changes of standard deviation were meant to reflect the expected increase in environmental stochasticity, namely higher drought and flood frequencies (IPCC, 2013). For each scenario, two different supplementary feeding regimes were considered: ad libitum SF and limited SF. Simulations were run 1000 times for 100 years each.

\section{Results}

A total of $n=374$ marked individuals across 17 capture occasions (1993-2009) were used in this analysis. Only a small amount of over-dispersion was found in the recapture data (c-hat $=1.593, X^{2}=89.2136$, degrees of freedom $=56, p=0.003$ ).

\subsection{POPAN model: Interaction of climate with abundance}

When using the complete dataset, this formulation generated a single best model in which survival was dependent on age, average temperature during the breeding season, the type of SF regime, average precipitation during the breeding season and the interaction between these last two variables. The equilibrium analysis yielded different influential environmental variables: only temperature was considered significant, regardless of the season (Table 1 and see Table C2, C3 in Supplementary material).

According to the complete model, abundance remained steady at approximately 30 individuals when limited SF was provided (see Fig. C1 in Supplementary material). However, after the ad libitum SF regime was implemented in 2000, population abundance increased sharply, reaching approximately 173 individuals in 2009 (Fig. C1). Abundance estimates derived from the equilibrium analysis followed the same trend and peaked at 169 individuals in 2009 (see Fig. C1). 
3.2 Pradel-recruitment model: Interaction between survival, recruitment and climate The complete candidate model set for this analysis included a total of six plausible models with $\triangle$ QAICc $<2$ (see Table C4 in Supplementary material); we thus used model averaging for these top models. Survival appeared to be influenced by temperature and precipitation during the breeding season whereas recruitment appeared to be affected by these weather variables during the non-breeding season (Table 1). The equilibrium analysis confirmed the importance of all environmental variables found in the complete models except for the impact of precipitation on survival, which was not a significant variable (Table 1 and see Table C5 in Supplementary material). Abundance, absent in the complete models' survival, was an important variable in the equilibrium analysis (Table 1), suggesting possible negative density dependence effects on survival (Fig. C3a).

Survival in the complete averaged model was dependent on age, sex, temperature and precipitation during the breeding season, the SF regime and the interaction between precipitation and the SF regime (Table 1). This interaction was positive: when the population was under an ad libitum SF regime, survival rates remained stable in wetter years, while they decreased under limited SF (Fig. 1a). Temperature had a negative impact on survival, but no buffering effect of SF was detected (Fig. 1b). There were no detectable differences between survival rates for the population under Ad libitum and limited SF (Fig. 1b). The equilibrium analysis suggests that the influence of precipitation and temperature during the breeding season on survival was much smaller (Fig. 1a, b).

For both complete and equilibrium analysis recruitment was dependent on abundance (possible density dependence effects), temperature and precipitation during the nonbreeding season and the interactions between these variables and the SF regime (Table 1). Overall, the population under an ad libitum SF regime had a higher predicted recruitment rate, with increases in temperature and in precipitation during the non-breeding season leading to a reduction of predicted recruitment (Fig. 1c, d). Under the limited SF regime, predicted recruitment was very low (Fig. 1c, d; Fig. C2c, d), which suggests that a large population could not be supported without ad libitum SF. These results are corroborated by the equilibrium models (Fig. 1c, d; Fig. C2c, d). Higher recruitment when averaging across all years than when just looking at years when population was at carrying capacity also revealed possible density dependence effects on recruitment (Fig. C3b).

\subsection{Population Dynamics Modelling}

Under current conditions (i.e. Baseline scenario), the abundance of a population receiving ad libitum SF was predicted to remain at $200\left(\mathrm{SD}=0.3\right.$; $\left.\mathrm{ER}_{\text {(baseline) }}=0 \%\right)$ or decrease to 56.9 individuals on average ( $S D=17.0$; extinction risk $E R_{\text {baseline }}=0 \%$ ) when models were parameterised with the equilibrium or complete dataset respectively.(Fig. 2a, 3a, Table 3). For the same scenario, a population receiving limited SF was predicted to stabilise at 26.1 individuals $\left(\mathrm{SD}=5.3, \mathrm{ER}_{\text {(baseline) }}=0 \%\right)$ or 12.1 individuals $\left(\mathrm{SD}=11.5 ; \mathrm{ER}_{\text {(baseline) }}=35.6 \%\right)$ when models were parameterised with the equilibrium or complete dataset respectively.

When compared to the Baseline scenario, the $10 \%$ decrease in precipitation did not appear to influence mean population abundance predicted with models parameterised with either datasets (Fig. 2a, 2c), but extinction risk predicted by the complete analysis for limited SF was considerably smaller ( $\mathrm{ER}_{\text {(baseline): }}$ : $35.6 \%$; $\mathrm{ER}_{\text {(drier) }}$ : $10.5 \%$ ) (Fig. 3). However, higher rainfall stochasticity was better for a population under an ad libitum SF regime than for one experiencing limited SF regime, regardless of the overall total rainfall (Fig. 2b, d). In these precipitation scenarios limited SF yielded different extinction risks depending on whether we use the complete or equilibrium parameterization (>90\% vs. $<0.1 \%$ respectively). 
The $1.8^{\circ} \mathrm{C}$ temperature increase almost always resulted in a very high extinction risk, with the only exception being the "Warmer" scenario under limited SF for the equilibrium analysis $\left(\mathrm{ER}_{\text {(warmer) }}=17.4 \%\right.$; Fig. $\left.2 \mathrm{e}, \mathrm{f} ; 3\right)$ and a very small mean population abundance.

Overall ad libitum SF allows a longer time to extinction than limited SF (Fig. 3). Moreover, predictions made from the equilibrium dataset (where the population is stable) were considerably more optimistic that when using the complete dataset.

\section{Discussion}

This study employed demographic analysis and stochastic population simulation models to assess how supplementary feeding (SF) can buffer the impact of changes in climate on the demographics of a threatened species, and its effectiveness as a conservation tool to alleviate climate change impacts on populations of endemic species. Little is known of how management can buffer threatened species against climate change, and understanding this relationship is urgently required as conservation managers seek alternatives in the face of current global environmental change predictions (Heller and Zavaleta, 2009). To our knowledge this study is the first to quantify the interaction between climate and management intensity of a threatened population.

Ad libitum SF has played an essential part in the spectacular growth of the hihi population reintroduced to Kapiti Island (Chauvenet et al., 2012). Here we have shown that this management strategy has probably buffered some of the negative demographic impacts on recruitment caused by fluctuations in total precipitation, particularly increased and more variable rainfall. Thus, SF likely has the potential to increase ecosystem resilience to more stochastic precipitation patterns. Such patterns can have catastrophic impacts on avian populations in general (Jenouvrier, 2013) and on the hihi, whose population dynamics have been found to be mainly driven by climate (Chauvenet et al., 2013). The buffering effect of SF we show likely reflects an increased reliability of food availability throughout the year: droughts and heavy rainfall influence flower phenology (Jentsch et al., 2009) and droughts have been linked to reduced nectar production which can impact nectar-feeding species negatively (e.g. Keasar et al., 2008), but SF is independent of precipitation patterns. Effects of precipitation on avian recruitment have been documented in the past: heavy rainfall can flood nests and kill fledglings while droughts can cause population-wide reproductive failure (Bolger et al., 2005; Jenouvrier, 2013). The different impact of precipitation on survival (positive) and recruitment (negative) is interesting. We are, however, unable to determine whether the negative effect on recruitment is due to a reduction in productivity (fewer individuals produced during more wet years) or juvenile survival (fewer juveniles recruiting into the population in more wet years). If the former is driving this relationship then our contrasting results may be revealing a life-history trade off in adult birds between investment in breeding versus survival. If the later, then it may be that juveniles are competitively disadvantaged during more wet years. Future research that directly measures productivity and juvenile survival would be required to test these alternative hypotheses.

Climate change is predicted to be particularly devastating for the hihi (Chauvenet et al., 2013). Average precipitation is expected to marginally decrease in New Zealand by 2100 while the frequency of extreme weather events, namely droughts and floods, is very likely to increase (IPCC, 2013). Moreover, average annual temperature in New Zealand is predicted to increase by at least $1.8^{\circ} \mathrm{C}$ by 2100 (IPCC, 2013) which, according to our models, will almost certainly cause the local extinction of the studied hihi population, regardless of SF. Ultimately, these changes may make much of the current range unsuitable for hihi (Chauvenet et al., 2013). We found that ad libitum SF may allow the hihi population on Kapiti Island to persist for a longer period of time than without management, particularly if rainfall stochasticity increases. Since flood frequency is expected to increase, even though New Zealand will become drier (IPCC, 2013), which would have a positive effect on hihi 
recruitment, ad libitum SF should still play a significant part in buffering impacts of heavy precipitation on vital rates.

When relating vital rates to climate variables, most differences found between the complete and the equilibrium analyses were merely qualitative: the equilibrium analysis revealed relationships similar but weaker than the ones found in the complete analysis. This could be due to two contrasting issues with the climate data during the 2005-2009 period. First, throughout this time period the values of precipitation during the breeding season were too consistent: precipitation during the breeding season was much less variable (average: 69.6 $\mathrm{mm} / \mathrm{month}$; range: $63.1-75 \mathrm{~mm} / \mathrm{month}$ ) when compared with the complete 2000-2009 time series (average: $71 \mathrm{~mm} / \mathrm{month}$; range: $36.8-117.2 \mathrm{~mm} / \mathrm{month}$ ). Such abnormally low variation in precipitation during the breeding season likely prevented us from accurately modelling the relationship between ad libitum SF and precipitation during the breeding season. This resulted in the most striking difference between both analyses: a lack of buffering effect of ad libitum SF on survival in the equilibrium model. Second, recorded values for the other environmental variables were too extreme: all but one of the minimum and maximum values of the remaining environmental variables registered between 2000 and 2009 were reported after 2004. Considering that only five data points were available for each variable, this could have desensitized the equilibrium analysis to the influence of extreme values. The weaker relationships between climate variables and demographic rates increased the importance of the remaining variables, resulting in more optimistic population projections by the equilibrium models. Nevertheless, both complete and equilibrium models show that for this population SF can play an important role as a climate change adaptation strategy, but only to buy time while alternative strategies are sought.

Other than a potential lack of statistical power of the equilibrium analysis, other factors could influence our results. First, assuming that all unbanded hihi caught in an October survey were one year old adults could eventually inflate estimated juvenile survival. In turn, we risk carrying such a bias into the population model projections and make predictions of extinction that are too conservative. In our case, the consequences of misattributing the age of individuals are unlikely to be significant because of observed high recapture rates, and the small number of individuals affected (ca. 10\%). Second, density dependence effects are known to influence reintroduced passerine population demography (e.g. Armstrong et al., 2005) and could eventually confound the climate buffering effects this study was trying to assess. As we took the necessary steps to detect and account for density dependence (considering abundance as a covariate in the Pradel-recruitment models and developing a separate set of models that compared the population at carrying capacity), we believe we have minimised any possible confounding effects.

The predicted climate change-driven gradual decrease in demographic gains provided by SF on Kapiti Island highlights the need for managers to critically review the efficacy of implemented conservation actions in the face of climate change. Methods to assist in making management decisions around SF and updating these decisions as conditions change has recently been reviewed by Ewen et al. (2014b). There are multiple valid management options to consider in cases such as the hihi. For example, the current method of SF relies on providing energy rich carbohydrates in the form of sugar water (Armstrong and Ewen, 2001; Armstrong et al., 2007; Chauvenet et al., 2012). Although we have shown that the current SF regime improves population viability of hihi in modified landscapes, it does not completely meet their balanced nutritional requirements due to their generalist diet (Walker et al., 2013). Therefore, current SF may not be the optimal supplement to provide as an adaptation strategy if, for example, non-carbohydrate nutrients, such as protein and fats, are more negatively impacted by climate change. Hence, SF efficiency could be increased if a more targeted match between predicted changes in food availability under climate change, nutrient requirements of a managed species and how these may be provided by SF is achieved. For instance, as ad libitum SF was found to buffer the impacts of more variable 
precipitation patterns, increasing the amount of sugar water provided during drought or flood events could potentially improve SF efficiency.

Another alternative management option proposed for species such as hihi is assisted colonisation, for which a number of suitable introduction sites have already been identified (Chauvenet et al., 2013). Assisted colonisation is particularly relevant for species that are 'trapped' on islands (virtual or real) when suitable habitat remains beyond their dispersal capability (Hunter, 2007). Despite being a controversial technique, assisted colonisations have already been undertaken in the past in response to climate change (Moir et al., 2011; Qie et al., 2012; Willis et al., 2009). In fact, it is predicted that this form of management will be increasingly more common in the future and, as such, has been incorporated in the recently updated international guidelines for conservation translocations (IUCN/SSC, 2013). Making management decisions for the best adaptation strategy to climate change will require a clear examination of ultimate desired outcomes for stakeholders and a thorough examination of alternative management options that may help managers achieve these outcomes.

Even though SF is a globally important management tool in threatened species conservation (Martínez-Abraín and Oro, 2013), we are currently unaware of any other detailed studies quantifying the role SF can play as a climate change adaptation tool. Only one other study was found that examined SF in the context of climate change. Furberg et al. (2011) studied how Sami reindeer herders in Sweden are coping with climate change, reporting that they are "facing the limit of resilience", but that SF is emerging as a solution to the threat posed by frozen and patchy pasturage. Nevertheless, Furberg et al. (2011) did not quantify the benefits of SF in the face of climate change. Therefore, our study is important and unique in not only quantifying to what extent SF can perform as an adaptation strategy, but by illustrating how important it is to continually reassess the efficiency of currently excellent management tools in the face of climate change as well.

\section{Conclusions}

During recent decades, ad libitum feeding probably buffered the negative impacts of heavier and more stochastic precipitation patterns on the hihi population of Kapiti Island. However, our results suggest that SF has been unable to fully guard the population against the negative impacts of increased temperature for an endemic island population of the hihi. Although our conclusion is that SF will not be able to avert the population's extinction on its own, it can still be considered as a valuable conservation strategy by delaying it.

Our work clearly demonstrates that intensive SF, a purposeful management tool for threatened species may not be efficient against the novel and global emerging threat that is climate change. We urge population managers to re-evaluate the efficiency of implemented management interventions in the face of this new threat if current management was not designed with it in mind. Moreover, on-going evaluation will be required as conditions change. If managers find that effectiveness of the chosen management strategies is predicted to decrease significantly, they will be faced with two options: (1) find a better adaptation tool for their population, which could be a combination of current approaches or a novel solution or (2) reconsider the cost-benefit ratio of safeguarding species against climate change, with the risk of deeming conservation projects unfeasible under this threat.

\section{Acknowledgments}

The authors thank the Department of Conservation coordinated hihi recovery group, the Kapiti Wellington Conservancy and Kapiti Island field staff for their on-going investment in hihi conservation. National hihi conservation benefits from funding from NZ Safety Ltd and the research presented here result from a Department of Conservation contract to John G. Ewen. The authors would also like to thank the two anonymous reviewers for their thoughtful comments and suggestions on an earlier draft of this manuscript. 


\section{References}

Armstrong, D.P., Castro, I., Griffiths, R., 2007. Using adaptive management to determine requirements of re-introduced populations: the case of the New Zealand hihi. J. Appl. Ecol. 44, 953-962. doi:10.1111/j.1365-2664.2007.01320.x

Armstrong, D.P., Davidson, R.S., Perrott, J.K., Roygard, J., Buchanan, L., 2005. Densitydependent population growth in a reintroduced population of North Island saddlebacks. J. Anim. Ecol. 74, 160-170. doi:10.1111/j.1365-2656.2004.00908.x

Armstrong, D.P., Ewen, J.G., 2001. Testing for food limitation in reintroduced hihi populations: contrasting results for two islands. Pacific Conserv. Biol. 7, 87.

Arnason, A.N., Schwarz, C.J., 1999. Using POPAN-5 to analyse banding data. Bird Study 46, S127-168. doi:10.1080/00063659909477242

Bellard, C., Bertelsmeier, C., Leadley, P., Thuiller, W., Courchamp, F., 2012. Impacts of climate change on the future of biodiversity. Ecol. Lett. 365-377. doi:10.1111/j.14610248.2011.01736.x

Bolger, D.T., Patten, M. a, Bostock, D.C., 2005. Avian reproductive failure in response to an extreme climatic event. Oecologia 142, 398-406. doi:10.1007/s00442-004-1734-9

Burnham, K., Anderson, D., 2002. Model selection and multimodel inference: a practical information-theoretic approach.

Cabezas, S., Moreno, S., 2007. An experimental study of translocation success and habitat improvement in wild rabbits. Anim. Conserv. 10, 340-348. doi:10.1111/j.14691795.2007.00119.x

Chauvenet, a. L.M., Ewen, J.G., Armstrong, D.P., Coulson, T., Blackburn, T.M., Adams, L., Walker, L.K., Pettorelli, N., 2012. Does supplemental feeding affect the viability of translocated populations? The example of the hihi. Anim. Conserv. 15, 337-350. doi:10.1111/j.1469-1795.2012.00522.x

Chauvenet, A.L.M., Ewen, J.G., Armstrong, D., Pettorelli, N., 2013. Saving the hihi under climate change: a case for assisted colonization. J. Appl. Ecol. 50, 1330-1340. doi:10.1111/1365-2664.12150

Clark, R.M., Thompson, R., 2010. Predicting the impact of global warming on the timing of spring flowering. Int. J. Climatol. 30, 1599-1613. doi:10.1002/joc

Clout, M.N., Elliott, G.P., Robertson, B.C., 2002. Effects of supplementary feeding on the offspring sex ratio of Kakapo. Biol. Conserv. 107, 13-18. doi:10.1016/S00063207(01)00267-1

Cooch, E., White, G.C., 2012. Program MARK - a gentle introduction, 11th ed.

Crick, H.Q.P., Dudley, C., Glue, D.E., Thomson, D.L., 1997. UK birds are laying eggs earlier CO 2 increases oceanic primary production Structural biology and phylogenetic estimation. Nature 388, 526-527.

DOC, D. of C., 2005. Hihi/stitchbird (Notiomystis cincta) recovery plan 2004-09. Threatened Species Recovery Plan 54., Threatened Species Recovery Plan 54. Wellington.

Elliott, G.P., Merton, D. V, Jansen, P.W., 2001. Intensive management of a critically endangered species: the kakapo. Biol. Conserv. 99, 121-133. doi:10.1016/S00063207(00)00191-9

Esler, A.E., 1967. The vegetation of Kapiti Island. New Zeal. J. Bot. 5, 353-393. doi:10.1080/0028825X.1967.10428753

Ewen, J.G., Renwick, R., Adams, L., Armstrong, D.P., Parker, K.A., 2014a. 1980 - 2011: 31 years of re-introduction efforts of the hihi (stitchbird) in New Zealand, in: Soorae, P.S. (Ed.), Global Re-Introduction Perspectives: 2014. IUCN/SSC Re-introduction Specialist Group, Gland, Switzerland.

Ewen, J.G., Walker, L., Canessa, S., Groombridge, J.J., 2014b. Improving supplementary feeding in species conservation. Conserv. Biol. in press. doi:10.1111/cobi.12410

Foden, W.B., Butchart, S.H.M., Stuart, S.N., Vié, J.-C., Akçakaya, H.R., Angulo, A., DeVantier, L.M., Gutsche, A., Turak, E., Cao, L., Donner, S.D., Katariya, V., Bernard, R., Holland, R. a, Hughes, A.F., O'Hanlon, S.E., Garnett, S.T., Sekercioğlu, C.H., Mace, G.M., 2013. Identifying the world's most climate change vulnerable species: a 
systematic trait-based assessment of all birds, amphibians and corals. PLoS One 8, e65427. doi:10.1371/journal.pone.0065427

Forrest, J.R.K., 2015. Plant-pollinator interactions and phenological change: what can we learn about climate impacts from experiments and observations? Oikos 124, 4-13. doi:10.1111/oik.01386

Furberg, M., Evengård, B., Nilsson, M., 2011. Facing the limit of resilience: perceptions of climate change among reindeer herding Sami in Sweden. Glob. Health Action 4, 1-11. doi:10.3402/gha.v4i0.8417

García-Ripollés, C., López-López, P., García-López, F., 2004. Management and monitoring of a vulture restaurant in Castellón Province, Spain. Vulture News 50, 5-14.

González, L.M., Margalida, A., Sánchez, R., Oria, J., 2006. Supplementary feeding as an effective tool for improving breeding success in the Spanish imperial eagle (Aquila adalberti). Biol. Conserv. 129, 477-486. doi:10.1016/j.biocon.2005.11.014

Grimm, V., Revilla, E., Groeneveld, J., Kramer-Schadt, S., Schwager, M., Tews, J., Wichmann, M.C., Jeltsch, F., 2005. Importance of Buffer Mechanisms for Population. Conserv. Biol. 19, 578-580.

Heller, N.E., Zavaleta, E.S., 2009. Biodiversity management in the face of climate change: A review of 22 years of recommendations. Biol. Conserv. 142, 14-32. doi:10.1016/j.biocon.2008.10.006

Hickling, R., Roy, D.B., Hill, J.K., Fox, R., Thomas, C.D., 2006. The distributions of a wide range of taxonomic groups are expanding polewards. Glob. Chang. Biol. 12, 450-455. doi:10.1111/j.1365-2486.2006.01116.x

Hulme, P.E., 2005. Adapting to climate change: is there scope for ecological management in the face of a global threat? J. Appl. Ecol. 42, 784-794. doi:10.1111/j.13652664.2005.01082.x

Hunter, M.L., 2007. Climate change and moving species: furthering the debate on assisted colonization. Conserv. Biol. 21, 1356-1358. doi:10.1111/j.1523-1739.2007.00780.x

IPCC, 2012. Glossary of Terms, in: Field, C.B., Barros, V., Stocker, T.F., Qin, D., Dokken, D.J., Ebi, K.L., Mastrandrea, M.D., Mach, K.J., Plattner, G.-K., Allen, S.K., Tignor, M., Midgley, P.M. (Eds.), A Special Report of Working Groups I and II of the Intergovernmental Panel on Climate Change (IPCC). Cambridge University Press, Cambridge, UK, and New York, NY, USA, pp. 555-564.

IPCC, 2013. Summary for policymakers, in: Stocker, T.F., Qin, D., Plattner, G.-K., Tignor, M., Allen, S.K., Boschung, J., Nauels, A., Xia, Y., Bex, V., Midgley, P.M. (Eds.), Climate Change 2013: The Physical Science Basis. Contribution of Working Group I to the Fifth Assessment Report of the Intergovernmental Panel on Climate Change. Cambridge University Press, Cambridge, United Kingdom and New York, NY, USA.

IUCN/SSC, 2013. Guidelines for reintroductions and other conservation translocations. IUCN Species Survival Commission, Gland, Switzerland.

Jenouvrier, S., 2013. Impacts of climate change on avian populations. Glob. Chang. Biol. 19, 2036-2057. doi:10.1111/gcb.12195

Jentsch, A., Kreyling, J., Boettcher-Treschkow, J., Beierkuhnlein, C., 2009. Beyond gradual warming: extreme weather events alter flower phenology of European grassland and heath species. Glob. Chang. Biol. 15, 837-849. doi:10.1111/j.1365-2486.2008.01690.x

Jump, A.S., Peñuelas, J., 2005. Running to stand still: adaptation and the response of plants to rapid climate change. Ecol. Lett. 8, 1010-1020. doi:10.1111/j.14610248.2005.00796.x

Keasar, T., Sadeh, A., Shmida, A., 2008. Variability in nectar production and standing crop, and their relation to pollinator visits in a Mediterranean shrub. Arthropod. Plant. Interact. 2, 117-123. doi:10.1007/s11829-008-9040-9

Lenoir, J., Gégout, J.C., Marquet, P. a, de Ruffray, P., Brisse, H., 2008. A significant upward shift in plant species optimum elevation during the 20th century. Science 320, 1768-71. doi:10.1126/science.1156831 
MacMahon, J.A., Holl, K.D., 2001. Ecological restoration: a key to conservation biology's future., in: Soulé, M.E., Orians, G. (Eds.), Research Priorities in Conservation Biology. Island Press, Washington, D.C., pp. 245-269.

Martínez-Abraín, A., Oro, D., 2013. Preventing the development of dogmatic approaches in conservation biology: a review. Biol. Conserv. 159, 539-547. doi:10.1016/j.biocon.2012.10.020

Moir, M.L., Vesk, P. a., Brennan, K.E.C., Hughes, L., Keith, D. a., McCarthy, M. a., Coates, D.J., Barrett, S., 2011. A preliminary assessment of changes in plant-dwelling insects when threatened plants are translocated. J. Insect Conserv. 16, 367-377. doi:10.1007/s10841-011-9422-7

Qie, L., Howard, S.D., Lim, S.L.-H., Sodhi, N.S., 2012. Assisted dispersal of tropical dung beetles. Raffles Bull. Zool. 25, 155-160.

R Development Core, T., 2013. R: A Language and Environment for Statistical Computing.

Schoech, S.J., Bridge, E.S., Boughton, R.K., Reynolds, S.J., Atwell, J.W., Bowman, R., 2008. Food supplementation: A tool to increase reproductive output? A case study in the threatened Florida Scrub-Jay. Biol. Conserv. 141, 162-173. doi:10.1016/j.biocon.2007.09.009

Thuiller, W., Lavorel, S., Araújo, M.B., Sykes, M.T., Prentice, I.C., 2005. Climate change threats to plant diversity in Europe. Proc. Natl. Acad. Sci. U. S. A. 102, 8245-50. doi:10.1073/pnas.0409902102

Walker, L.K., Armstrong, D.P., Brekke, P., Chauvenet, a. L.M., Kilner, R.M., Ewen, J.G., 2013. Giving hihi a helping hand: assessment of alternative rearing diets in food supplemented populations of an endangered bird. Anim. Conserv. 16, 538-545. doi:10.1111/acv.12026

Wilbur, S.R., Carrier, W.D., Borneman, J.C., 1974. Supplemental feeding program for California condors. J. Wildl. Manage. 38, 343-346.

Willis, S.G., Hill, J.K., Thomas, C.D., Roy, D.B., Fox, R., Blakeley, D.S., Huntley, B., 2009. Assisted colonization in a changing climate: a test-study using two U.K. butterflies. Conserv. Lett. 2, 46-52. doi:10.1111/j.1755-263X.2008.00043.x

\section{Supplementary material}

Additional Supplementary material may be found in the online version of this article.

Figure A1: Schematic describing the demographic model selection process.

Text B1: Model averaging protocol

Table C1. Pradel-recruitment averaged top model parameters.

Table C2. Full POPAN candidate model set from the complete analysis.

Table C3. Full POPAN candidate model set from the equilibrium analysis.

Table C4. Selection of the top Pradel-recruitment models from the complete analysis.

Table C5. Selection of the top Pradel-recruitment models from the equilibrium analysis.

Figure C1. Hihi abundance on Kapiti Island.

Figure C2. Female adult hihi survival and recruitment trends predicted by the developed Pradel-recruitment model as a function of climate variables.

Figure C3. Density dependence effects of ad libitum SF relative to limited SF on female adult hihi.

\section{Tables}

Table 1. Covariates tested for in each parameter of the POPAN and the Pradel-recruitment models developed for both equilibrium and complete datasets. $\mathbf{X}$ indicates parameter covariates included in both top model sets, $\mathbf{C}$ indicates covariates included in the complete top model set, $\mathbf{E}$ indicates covariates included in the equilibrium top model set and $\mathrm{O}$ indicates covariates considered that were not included in any top model. Age represents differential survival between 1st year adults and all other adults; Sex represents the gender of the individuals; in the Complete analysis SF Regime includes 2 supplementary feeding regimes: limited SF (1993-1999) and ad libitum SF (2000-2009); in the equilibrium analysis ad libitum was calculated from data from 2005-2009; Abundance is the yearly abundance 
estimates yielded by the POPAN model; Breed Temperature and Breed Precipitation represent the average temperature and the total precipitation during the Breeding Season (September to March); Non-Breed Temperature and Non-Breed Precipitation are the same variables for the Non-Breeding Season (April to August); * represents an interaction between 2 covariates; POPAN's super-population size $N$ is assumed to be constant; covariates were considered significant if QAICc $<2$.

$\boldsymbol{\varphi}_{i}$ : probability of an individual surviving between occasions $i$ and $i+1 ; p_{i}$ : probability of capture at occasion $i$; pent; : probability that an individual from the super-population $N$ enters the population between occasion $i$ and $i+1 ; \boldsymbol{f}_{i}$ : number of new individuals that enter the population per breeding adult in year $i$ that are still alive by $i+1$.

\begin{tabular}{|c|c|c|c|c|c|}
\hline \multirow{2}{*}{ Covariates } & \multicolumn{2}{|c|}{ POPAN } & \multicolumn{3}{|c|}{ Pradel-recruitment } \\
\hline & $\varphi_{i} \quad p$ & pent $_{i}$ & $\varphi_{i}$ & $\overline{f_{i}}$ & $p_{i}$ \\
\hline Age & $\mathbf{X}$ & & C & & \\
\hline Sex & $\mathrm{O}$ & & $\mathbf{X}$ & & \\
\hline SF Regime & $\mathbf{X}$ & & $\mathbf{x}$ & $\mathbf{X}$ & \\
\hline Abundance & & & $\mathbf{E}$ & $\mathbf{X}$ & \\
\hline Time & $\bar{x}$ & $\mathbf{X}$ & & & $\mathbf{X}$ \\
\hline Breed Temperature & $\mathbf{X}$ & & $\mathbf{X}$ & $\mathrm{O}$ & \\
\hline Breed Precipitation & C & & $\mathbf{C}$ & $\mathrm{O}$ & \\
\hline Non-Breed Temperature & $\mathbf{E}$ & & $\mathrm{O}$ & $\mathbf{X}$ & \\
\hline Non-Breed Precipitation & $\mathrm{O}$ & & $\mathrm{O}$ & $\mathbf{X}$ & \\
\hline Breed Temperature * SF Regime & $\mathbf{E}$ & & $\mathrm{O}$ & $\mathrm{O}$ & \\
\hline Breed Precipitation * SF Regime & C & & $\mathbf{C}$ & $\mathrm{O}$ & \\
\hline Non-Breed Temperature * SF Regime & 0 & & $\mathrm{O}$ & $\mathbf{X}$ & \\
\hline Non-Breed Precipitation * SF Regime & 0 & & $\mathrm{O}$ & $\mathbf{X}$ & \\
\hline Abundance * SF Regime & & & $\mathbf{R}$ & $\mathbf{X}$ & \\
\hline
\end{tabular}

Table 2. List of the climate change scenarios modelled; $X$ indicates the change modelled. 'Base' corresponds to the average climate conditions observed during our study. 'Mean Temp' corresponds to the average annual temperature between 1993 and 2009; 'Precip' corresponds to the total annual precipitation between 1993 and 2009; 'SD' is standard deviation.

\begin{tabular}{llll}
\hline Scenario code & +1.8 C Mean Temp & $-10 \%$ Precip & Precip SD * 2 \\
\hline Base & - & - & - \\
\hline Variable precip. & - & - & $X$ \\
\hline Drier & - & $X$ & - \\
\hline Drier \& more variable precip. & - & $X$ & $X$ \\
\hline Warmer & $X$ & - & - \\
\hline Warmer \& drier & $X$ & $X$ & - \\
\hline
\end{tabular}




\section{Figures}
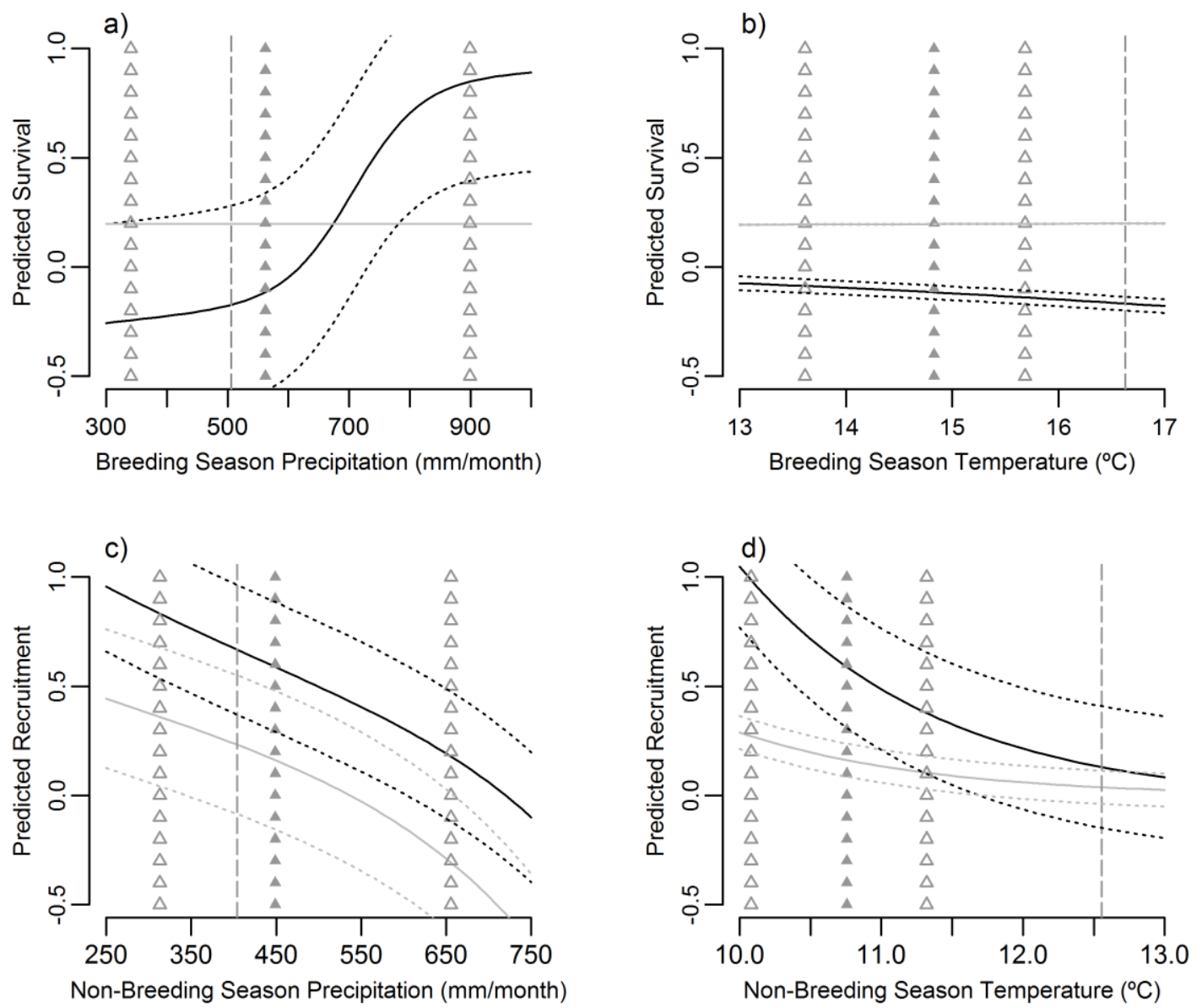

Fig. 1. Buffering effect of ad libitum SF relatively to limited SF on female adult hihi survival and recruitment rates. Buffering effect was calculated by subtracting limited SF trend lines from ad libitum SF trend lines predicted by the developed Pradel-recruitment model as a function of climate variables. Survival is modelled according to precipitation (a) and temperature (b) during the Breeding Season. Recruitment is modelled as a function of precipitation (c) and temperature (d) during the Non-Breeding Season. All variables and interactions modelled are identified in Table 1. Black curves: model fit to 2000-2009 dataset (complete model). Grey curves: model fit to 2005-2009 dataset when population was deemed stable (equilibrium model). Dotted curves: upper and lower 95\% confidence intervals. Filled triangles: average precipitation/temperature between 1993 and 2009. Hollow triangles: minimum and the maximum values observed during the study period. Vertical grey dashed line: IPCC prediction for average precipitation/temperature in 2100 (RCP 4.5 scenario). Other climate variables in the model were held at their mean values. Abundance was set at 50 individuals. 
a) Baseline

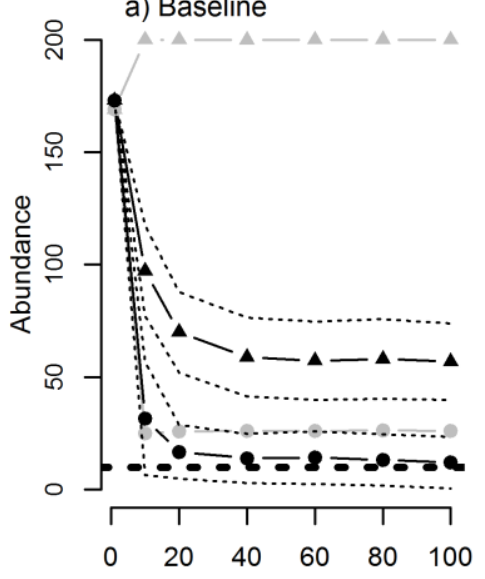

b) Variable precip.

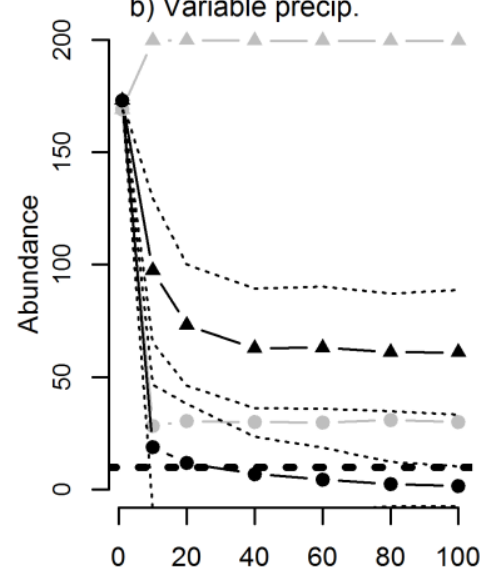

e) Warmer
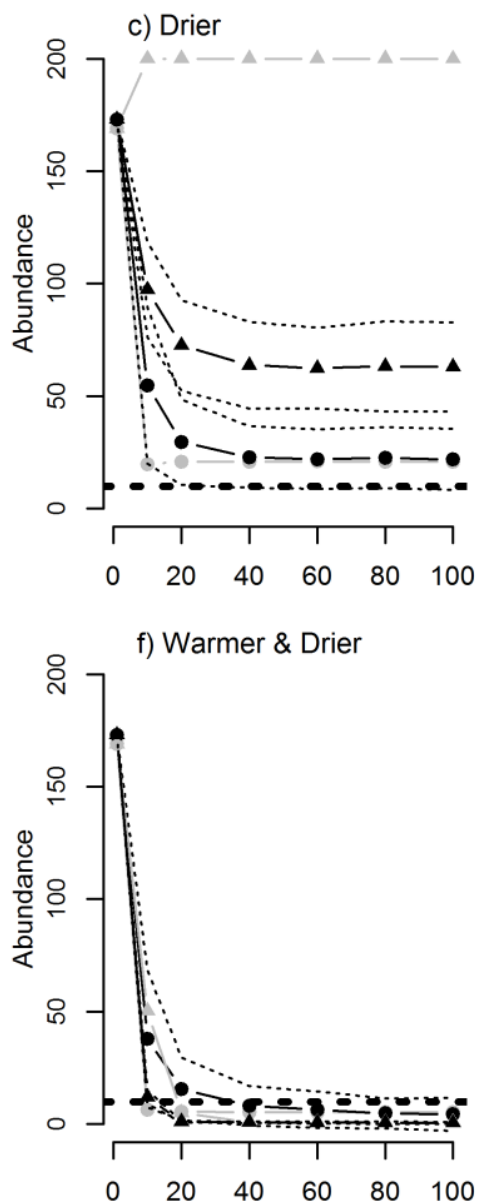
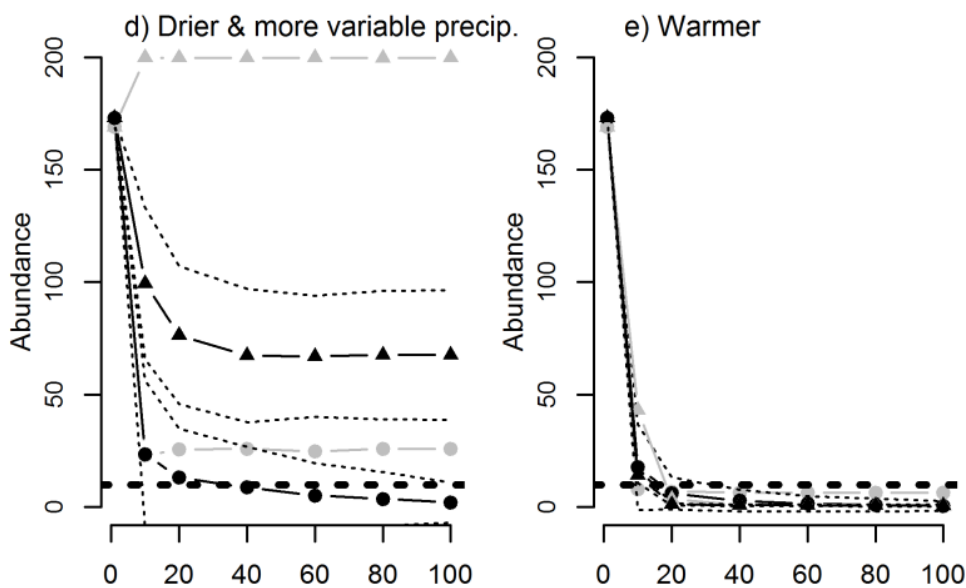

Fig. 2. Estimated impacts of different climate change scenarios on average population size over 100 years. Two distinct SF regimes were tested for: ad libitum SF (filled triangles) and limited SF (filled circles). Black lines: ad libitum was modelled from data from 2000-2009 (complete model). Grey lines: ad libitum was modelled from data from 2005-2009 (equilibrium model). Dashed lines: upper and lower confidence intervals for the complete analysis. For clarity, standard deviation (SD) is only shown for the complete analysis. Bold dotted line: critical minimum population size (5 individuals). Climate change scenarios tested were relative to 1993-2009 weather conditions: a) Baseline: corresponds to 1993-2009 climate conditions; b) Variable precip.: Double SD of precipitation; c) Drier: $10 \%$ decrease in total precipitation; d) Drier \& more variable precip.: $10 \%$ decrease in total precipitation and precipitation SD $\times 2$; e) Warmer: $1.8^{\circ} \mathrm{C}$ increase in yearly average temperature; and f) Warmer \& drier: $1.8^{\circ} \mathrm{C}$ increase in yearly average temperature and $10 \%$ decrease in total precipitation. 


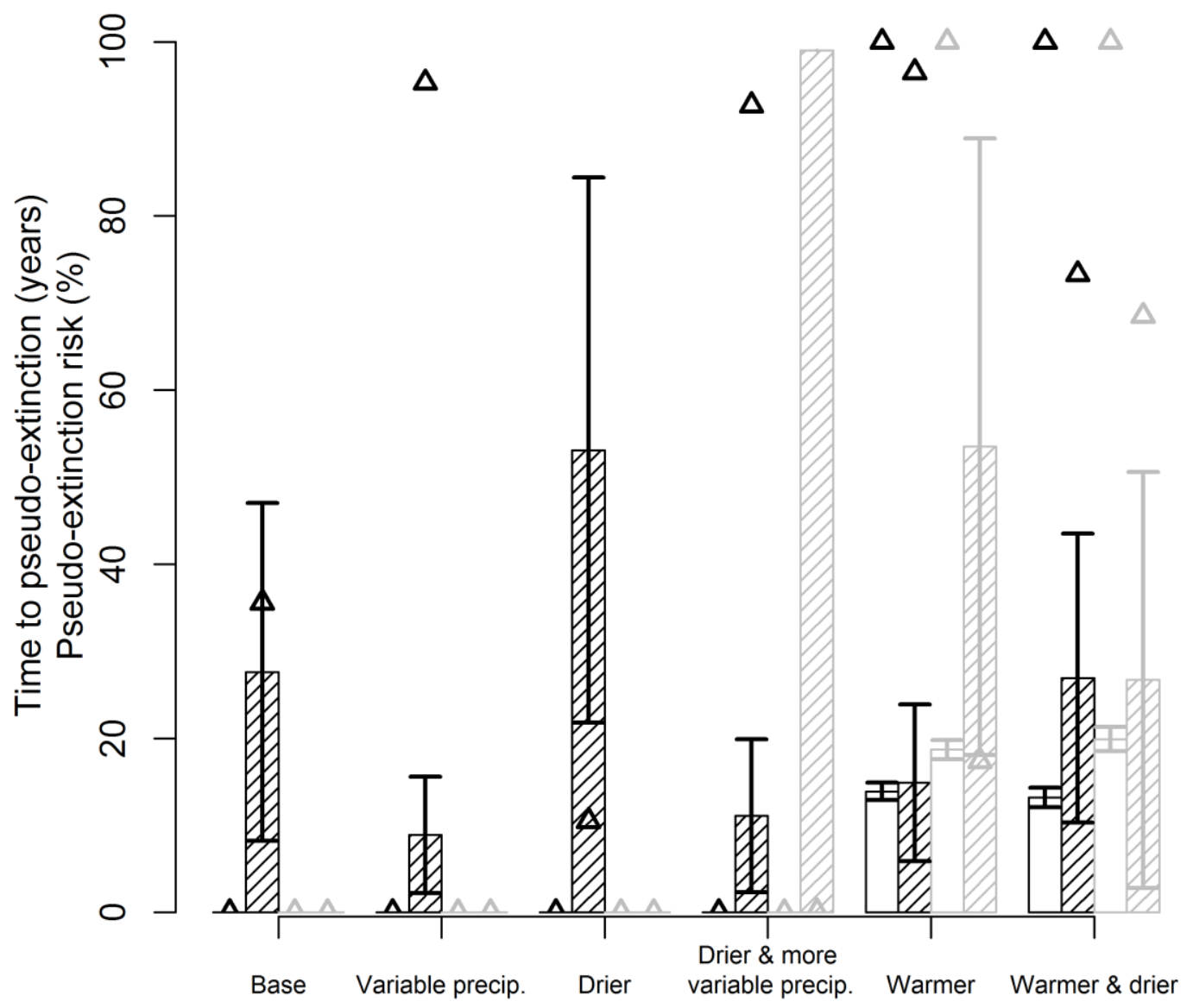

Fig. 3. Pseudo-extinction risk (hollow triangles; \%) and average time to pseudo-extinction (columns; years) derived from the predictive models used to simulate future hihi population abundance under several climate change scenarios over 100 years. Populations were considered extinct if abundance $\leq 5$. Dark symbols: ad libitum modelled from data from 2000-2009 (complete model). Grey symbols: ad libitum modelled from data from 2005-2009 (equilibrium model). Hollow columns: ad libitum SF. Striped columns: limited SF. Vertical lines represent standard deviation of average time to pseudo-extinction. 